\title{
Whether Hypertensive Diseases in Pregnancy are Associated with Emotional Stress
}

\author{
Dr Zahida Liaqat Dr Samia Gull Dr Samiea Parveen Dr Afsheen Rasheed \\ Consultant Gynaecologist Rajab Tayyep Erdogan Indus Hospital, Muzaffargerh
}

\begin{abstract}
Objective :Stress plays important role in effecting the cardiovascular disease and most of the risk factors with hypertensive disease in pregnancy [HDP] is caused by stress. Main objective of the study is to find connection between stress and risks for HDP during pregnancy. Place and duration of study: Obstetrics and Gynaecology Department Rajab Tayyep Erdogan Indus Hospital, Muzaffargerh. From August 2018 to August 2019. Material and method:A controlled examination contrasting obstetrical and psychosocial was conducted by 724 patient and 879 matched control for ages, equality, and educational level. Results: Emotional stress during pregnancy was linked with 1.6 times increase risk for hypertension during pregnancy.
\end{abstract}

Conlusion :Psychosocial involvement to decrease emotional stress during the period of pregnancy can aid to reduce the risk to emerge HDP.

Keywords: Hypertensive, Pregnancy, Emotional Stress

DOI: $10.7176 / \mathrm{JMPB} / 60-04$

Publication date:October $31^{\text {st }} 2019$

\section{Introduction}

Pregnancy in nulliparous females is effected by preclampsia from 2-6\%. ${ }^{[1-3]}$ Most significant reason for mother death in pregnancy is hypertensive disease diseases in pregnancy. ${ }^{[1-3]}$ In the developed countries, $15-20 \%$ of total case of premature deaths and $19 \%$ of periantal death have contribution to such diseases. ${ }^{[1,4,5]}$ aside from actual delivery time, no intercession for usual therapy of HDP are well-known. Thus, decrease in risk for HDP is very significant.

Preclampsia evolves in 2 phase. In the phase 1, unusual placentation causes reduction in placental prefusion. Also, other factor have to accompany unusual placentation to initiate phase 2 that leads to general diseases, i.e. preclampsia, low platelet syndrome, heamolysis etc. ${ }^{[7]}$ the present hypothesis of multifacet etiology includes the connection of pre-pregnancy BMI, immune mal-adaptation, oxidative stress and genetically susceptible is allowed. ${ }^{[1,6]}$ several medical and clinical outcome gives significance to hypothesis that stress also involves in the physiology of HDP, the frequency of HDP is specifically higher in young and elder mother ${ }^{[1,7]}$, both of these are experienced to high degree of psycosocial strains, that is usually because of high number of uncertain pregnancies. ${ }^{[8]}$ The SNS is known to apply aa significant impact on some organ system ivolves in the progress of HDP,e.g. metabolism of lipids, endothelium, cardiovascular system. ${ }^{[9-14]}$ the studies of human being as well as animal's revealed a connection between activation of SNS due to different aggravation and symptoms of preclampsia and HELLP syndrome ${ }^{[9-11]}$. for instance, the most common risk in HDP is overweight, that reduces the vagal activity ${ }^{[16]}$. when the activity of sympathetic nervous system is stopped due to epidural anesthesia, reduction in the symptom and biochemical standards of disease occurred. ${ }^{[12,17]}$

But it is still not known, that why the females suffering with HDP suffers from cardiac disease later in their life ${ }^{[7]}$. During the period of pregnancy, portion of fundamental pathophysiological mechanism may becomes prominent, and also might be used to decrease the longer outcomes. In comparison to other dangerous factors, emotional factor present a chance for prophylaxis. Thus, main objective of the study was to find the connection between stress during the period of pregnancy and possibility for HDP.

\section{Material and methods}

The consequences have been togethered within worldwide research projects evaluating the function of epidemiological and psychosocial factor in the aetiology and courses of HDP. This is case-controlled study contrasting data from the females having HDP to matched control females was conducted in Obstetrics and Gynaecology Department Rajab Tayyep Erdogan Indus Hospital, Muzaffargerh. From August 2018 to August 2019. Only the women having pregnancy within 2 year before the survey were included in the study. Patient's records must show 1 HDP. Gestational hypertension $[\mathrm{GH}]$ and $[\mathrm{CH}]$,B.P should be greater or equal to $145 / 95 \mathrm{~mm}$ $\mathrm{Hg}$ before or after twenty week of pregnancy, preclamosia $=\mathrm{GH} / \mathrm{CH}+$ proteinuria [ less or equal to $0.29 \mathrm{~g}$ in twenty-four hour urine sample], HELLP syndrome, aspartate aminotransferase greater or equal to STD, platelate count less or equal to $100 \mathrm{G} / \mathrm{L}$. Controlled females were eliminated when these were suffered from Long-term hypertension , HDP, BP greater or equal 145/95mmHg during pregnancy. Also, for applying the same elimination criteria to patient and control, females suffering hyper-hypothyroidism or diabetes mellitus were eliminated from the both group. All the women having first pregnancy were considered for evaluation, that was considered as first 
pregnancy complex by hypertension and evaluated on 24 week of pregnancy. Patients were contrasted to control females for risk factors of HDP like age of mother, nationality, level of education. Written consent were signed from the patients. The study was completed according the ethical committee of hospital.

\section{Statistical analysis}

The dissamilatities between the proportion were examined by the use of chi-square test. Oginizational regression model evaluated the link between HDP and emotional stress during pregnancy. Forward regression model including variable that was $\mathrm{p}<0.05$ effected risk of HDP in the different analysis. Data analysis was done by using SPSS computer software.

\section{RESULTS}

After contrasting the data of 724 patient and 870 control female were accessible for inspection. From 724 patient , 99 (13.1\%) suffered from gestational hypertension, 300 (41.4\%) suffered from preclampsia, and $325(44.8 \%)$ had HELLP- syndrome .

Table No.1

Sociodemographic factors for patient and control females.

\begin{tabular}{|c|c|c|}
\hline variables & $\mathrm{HDP}(\mathrm{N}=724)$ & Control(N=879) \\
\hline Ages of females (average) & $29.6 \%$ & $29.2 \%$ \\
\hline Education level & $0.4 \%$ & $0.5 \%$ \\
\hline Married percentage & $97.6 \%$ & $97.7 \%$ \\
\hline
\end{tabular}

One hundred and thirty patients and 75 control females suffered from abortion to index-pragnancy . the number of miscarriages before the indexpragnancy was importantly greater in females suffering from HDP contrasted to control female, table number 2 is showing stress during pregnancy.

Table No.2

Stress during pregnancy

\begin{tabular}{|l|l|l|l|}
\hline Stress level & Control [N/\%] & HDP[N/\%] & P-value \\
\hline None & $405 / 46.2$ & $140 / 19.3$ & $<0.0001$ \\
\hline less & $173 / 19.6$ & $146 / 19.7$ & ns \\
\hline Medium & $160 / 18.2$ & $160 / 20.1$ & $<0.05$ \\
\hline severe & $70 / 7.9$ & $155 / 21.4$ & $<0.0001$ \\
\hline Very severe & $71 / 8.1$ & $123 / 17.0$ & $<0.0001$ \\
\hline
\end{tabular}

The assessment of strain during pregnancy was same in females after HDP having healthy baby or those with baby suffering from a kind of abnormality contrasted to control females. For both categories of females with HDP small level of strain was described significantly less often, on the other hand, stress which is severe or very severe was described significantly much more than that of control females. Main reason of stress were same in patients and controls. In both categories three main significant reason for stress during the period of pregnancy were the mother's injury or death of the friend or relative, or illness or family or friend. Females having HDP explained significantly marital confls, financial issues, also alteration in the habitate. This study explained that 1.6 times increased threat of HDP happened during period of pregnancy in stress's case. Threat of preclampsia during the pregnancy increases by 2.1 folds due to stress and risk of HELLP syndrome by 1.6 folds.

\section{DISCUSSION}

In this study, in following to another survey on aggravation during pregnancies ${ }^{[25]}$ patients declared remarkably much severe emotional strain during the time of their pregnancies when contrasted to controls[ table no.2]. the impact of aggravation on the initiation of HDP may be elaborated by a lot of processes. Important symptoms that is related to stress is hypertonia ${ }^{[12,31-33]}$. preclampsia in human is linked with sympathetic activity, and elevation of sympthattic activity causes symptoms, also alteration in the lab standards usuall for HDP ${ }^{[11,14,34]}$. For instance, It causes the actuation and aggregation of thrombocyte, alteration of coagulation, endothelial dysfunction, which may remains from week till month after taking event. ${ }^{[33,35,36]}$

Main role of emotional stress as threat factor for HDP is also aided by the fact that HDP and heart diseases represent common threat factor. In cardiac diseases the impact of severe stress has been observed to be equivalent to the impact of conventional threat factors like overweight or nicotine addiction ${ }^{[32,33]}$.

Apparently, identification of HDP is also reason for more strain and anxiety. Also, in initial phase oof placentation, stress causes decreased trophoblast invasion. ${ }^{[36]}$ initial involment of stress has also represented in the related studies, in which catecholamines elevated prior the expansion of HDP. ${ }^{[37]}$ thus the activation of SNS by stress appears to be definite reason of disease and not the outcome of the identification of HDP. Additionally to the stress experienced during pregnancy, the patient had suffered from abortions before to the index-pregnancy, in few cases above 5 times. Mostly, recurrent abortion is most common to carry the threat for stress in the 
subsequent pregnancy. ${ }^{[38]}$ When the life of patients and controls contrasted, they suffered from same stress during the pregnancy period. Therefore, during the pregnancy period not only straning events of life but according to SPSS stress was much in patient presenting HDP when contrasted to controls. Those outcomes represented were in line with those of Rippman and colleague ${ }^{[25]}$, expresses that stress related to job is stressor for HDP. But it was not confirmed by them, that in the duration of pregnancy financial buden is linked with elevating threat of HDP.

Difference between the pateunt and controls was remarkable for females having preclampsia, but not significant for patients with gestational hypertension. Gestational hypertension is less harmful hypertensive problem during pregnancy as it is not much harmful for new born and mother. Threat of preclampsia during the pregnancy increases by 2.1 folds due to stress and risk of HELLP syndrome by 1.6 folds. Psychological stress is much more linked with hypertension ${ }^{[21,31-33]}$, that is the symptom of preclampsia bit not the symptom of HELLP syndrome, this may explain that why the impact of preclampsia is strong than on HEELP syndrome. Difference in risk factors of both categories of HDP have shown other risk factors like addiction of nicotine. ${ }^{[22,39]}$. However, development of stress may be useful approach to reduce the threat of preclampsia and HELLP syndrome. These therapy option have proved to be successful in the cardiac diseases. ${ }^{[32,33,40]}$ psychotherapy during the period of pregnancy can decrease the symptoms of HDP. ${ }^{[28]}$ in additton, eexcercise is helpful in decreasing the effect of stress. ${ }^{[31,32]}$. also, decrease in the stress in the pragnancy may decrease other complication like premature birth of baby. ${ }^{[42]}$

Main drawback of the study is that the assessment of the effects of stress is much hard to measure. Stress has different sides and includes severe experience and assessmbled effect of lifetime exposure to crises. ${ }^{[43]}$ Addition to this, explained stressors are knowledgeable differently by all female. ${ }^{[44]}$ assessment of stress has been used in combinations with stress test to command for separate difference of stress perception. ${ }^{[45]}$ In the survey, we didn't differentiate in stressors that occurs in distinct period of gestational age. As HDP occurs in two phases, it looks like there are important endangered phases, where stress has more noticeable impact than during different time of pregnancy. Thus, writer can not exclude that in some females the stress normally appears after the initiation of the diseases, that leads to high estimation of connection between stress and the threat of HDP. Thus , future investigators will have to study, whether the impact of stressful incidents have effect on gestational age oe whether a high strain levels prior to pregnancy shows a susceptibility for HDP.

Outcomes and categories of recent outcomes directing on the pathophysiology of HDP carry the hypothesis that stress in the duration of pregnancy causes the threat for spreading HDP. Well-organized psychological involvement supplies low-cost prophylaxis that can ameliorate prenatal care for females at that for HDP. As a result, assessment of stress and connected coping procedures must be part of prenatal care.

\section{REFERENCES}

1. Roberts JM, Pearson G, Cutler J, Lindheimer M. Summary of the NHLBI Working Group on Research on Hypertension during Pregnancy. Hypertension 2003;41(3):437-445.

2. Hauth JC, Ewell MG, Levine RJ. Pregnancy outcomes in healthy nulliparas who developed hypertension: Calcium for pre-eclampsia prevention study group. Obstet Gynecol 2000;95:24-28.

3. Knuist M, Bonsel GJ, Zondervan HA, Treffers PE. Intensification of fetal and maternal surveillance in pregnant women with hypertensive disorders. Int J Gynaecol Obstet 1998;61:127-133.

4. Meis PJ, Goldenberg RL, Mercer BM. The preterm prediction study: risk factors for indicated preterm births: Maternal-Fetal Medicine Units Network of the Hypertens Pregnancy 2007.26:211-226. National Institute of Child Health and Human Development. Am J Obst Gyn 1998;178:562-567.

5. Solomon CG, Seely EW. Pre-eclampsia: searching for the cause. N Engl J Med 2004;350:641-642.

6. Roberts JM. Preeclampsia: What we know and what we do not know. Sem in Perinatol 2000;24(1):24-28.

7. Broughton Pipkin F, Roberts JM. Hypertension in pregnancy. J Hum Hypertens 2000;14:705-724.

8. Wenderlein JM. Gestose und Psychosomatik. Zbl Gynäkol 1983;105(105): 1457-1467.

9. Khatun S, Kanayama N, Belayet HM, Masui M, Sugimura M, Kobayashi T, et al. Induction of preeclampsia like phenomena by stimulation of sympathetic nerve with cold and fasting stress. Eur J Obstet Gynecol Reprod Biol 1999;86:89-97.

10. Kanayama N, Tsujimura R, She L, Maehara K, Terao T. Cold-induced stress stimulates the sympathetic nervous system, causing hypertension and proteinuria in rats. J Hypertens 1997;15(4):383-389.

11. Schobel HP, Fischer T, Heuszer K, Geiger H, Schmieder RE. Preeclampsia - a state of sympathetic overactivity. N Engl J Med 1996;335:1480-1485.

12. Khatun S, Kanayama N, Sato E, Belayet HM, Kobayashi T, Terao T. Eclamptic plasma stimulates norepinephrine release in cultures sympathetic nerve. Hypertension 1998;31:1343-1349.

13. Sharpley CF, Kamen P, Galatsis M, Heppel R, Veivers C, Claus K. An Examination of the Relationship between resting heart rate variability and heart rate reactivity to a mental arithmetic stressor. Appl Psychophys Bio 2000;25(3):143-153.

14. Levinsky RM, Riskin-Mashiah S. Autonomic imbalance in Preeclampsia: Evidence for increased sympathetic 
tone in response to the supine-pressor test. Obstet Gynecol 1998;91:935-939.

15. Zahorska-Markiewicz B, Kuagowska E, Kucio C, Klin M. Heart rate variability in obesity. Int J Obes Relat Metab Disord 1993;17:21-23.

16. Innes KE, Wimsatt JH. Pregnancy-induced hypertension and insulin resistance: evidence for a connection. Acta Obstet Gynecol Scand 1999;78:263-284.

17. Ramos-Santos E, Devoe LD, Wakefield ML, Sherline DM, Metheny WP. The effects of epidural anaesthesia on the Doppler velocimetry of umbilical and uterine arteries in normal and hypertensive patients during active term labor. Obstet Gynecol 1991;77:20-26.

18. Leeners B, Rath W, Kuse S, Neises M, Neumaier-Wagner P. Satisfaction with medical information in women with hypertensive disorders in pregnancy. J Psychosom Res 2006;60(1):39-44.

19. Leeners B, Rath W, Kuse S, Neises M, Neumaier-Wagner P. The significance of under- or overweight during childhood as a risk factor for hypertensive diseases in pregnancy. Early Hum Dev 2006;82(19):663-668.

20. Leeners B, Rath W, Kuse S, Neises M, Neumaier-Wagner P. Family stability during childhood and the risk to develop hypertensive diseases in pregnancy. Early Hum Dev 2006;82(7):441-446.

21. Leeners B, Rath W, Kuse S, Neumaier-Wagner P. Breast-feeding in women with hypertensive disorders in pregnancy. J Perinat Med 2005;33(6):553-60.

22. Leeners B, Rath W, Kuse S, Irawan C, Imthurn B, Neumaier-Wagner P. BMI: New aspects of a classical risk factor for hypertensive disorders in pregnancy. Clin Sci (Lond) 2006;111:81-86.

23. Brown M, Lindheimer M, de Swiet M, Van Assche A, Moutquin J-M. The classification and diagnosis of the hypertensive disorders of pregnancy: statement from the International Society for the Study of Hypertension in Pregnancy (ISSHP). Hypertens Pregnancy 2001;20:9-14.

24. Audibert F, Friedman SA, Frangieh AY, Sibai B. Clinical utility of strict diagnostic criteria for the HELLP (hemolysis, elevated liver enzymes, and low platelets) syndrome. Am J Obstet Gynecol 1996;175:460-464.

25. Rippmann ET. EPH-Gestose. Berlin, New York: de Gruyter; 1972.

26. Eicher W. Psychosomatische Aspekte der EPH-Gestose. Psychosom Med 1973(5):120-127.

27. Crandon AJ. Maternal anxiety and obstetric complications. J Psychosom Res 1978;23:109-111.

28. Bung P, Rüddel H, Bähr M. Über die Ätiologie von Gestosen: ein eigener Beitrag unter besonderer Wertung des psychosomatischen Gesichtspunktes. In: Stauber M, Conrad F, Haselbacher G, editors. Jahresband Psychosomatische Gynäkologie 1991. Berlin: Springer; 1991.

29. Holmes T, Rahe R. The social readjustment rating scale. J Psychosom Res 1967;11:213-218.

30. Latman NS, Walls R. Personality and stress: an exploratory comparison of rheumatoid arthritis and osteoarthritis. Arch Phys Med Rehabil 1996;77:796-800.

31. Brownley KY, Hinderliter AL, West SG, Girdler SS, Sherwood A, Light KC. Sympathoadrenergic mechanisms in reduced hemodynamic stress responses after exercise. Med Sci Sports Exerc 2003;35(6):978986.

32. Williams RB, Barefoot JC, Schneidermann N. Psychosocial Risk Factors for Cardiovascular Disease. JAMA 2003;290(16):2190-2192.

33. Rozanski A, Blumenthal JA. Impact of psychological factors on the pathogenesis of cardiovascular disease and implications for therapy. Circulation 1999;99(16):2192-2217.

34. Gant NF, Chand S, Worley RJ, Whalley PJ, Crosby UD, MacDonald PC. A clinical test useful for predicting the development of acute hypertension in pregnancy. Am J Obstet Gynecol 1974;120:1-7.

35. Larsson PT, Wallen NH, Hjemdahl P. Norepinephrine-induced human platelet activation in vivo is only partly counteracted by aspirin. Circulation 1994;89:1951-1957.

36. Kanayama N, Tsujimura R, She L, Maehara K, Terao T. Cold-induced stress stimulates the sympathetic nervous system causing hypertension and proteinuria in rats. J Hypertens 1997;15:383-389.

37. Natrajan PG, McGarrigle HH, Lawrence DM, Lachelin C. Plasma noradrenaline and adrenaline levels in normal pregnancy and in pregnancy-induced hypertension. Br J Obstet Gynaec 1982;89:1041.

38. Klock SC, Chang G, Hiley A, Hill J. Psychological distress among women with recurrent spontaneous abortion. Psychosomatics 1997;38(5):503-507.

39. Leeners B, Rath W, Kuse S., P. N-W. Smoking in women is associated with a strongly reduced risk for HELLPsyndrome and to a lesser degree with the Hypertens Pregnancy 2007.26:211-226. abridged risk for preeclampsia and gestational hypertension. Acta Obst Gynecol Scand 2006;85(10):1217-1224.

40. Castillo-Richmond A, Schneider RM, Alexander CN. Effects of stress reduction on carotid atherosclerosis in hypertensive African Americans. Stroke 2000;31:568-573.

41. Task Force of the European Society of Cardiology and the North American Society of Pacing Electrophysiology. Heart rate variability, standards of measurement, physiological interpretation and clinical use. Circulation 1996;93(5):1043-1065.

42. Ruiz RJ, Fullerstone J, Dudley DJ. The interrelationship of maternal stress, endocrine factors and inflammation on gestational length. Obstet Gynecol Surv 2003;58(8):415-428. 
43. Hogue CJ, Bremner JD. Stress model for research into preterm delivery among black women. Am J Obstet Gynecol 2005;192(5 Suppl):S47-55.

44. Verres R. Die Kunst zu leben—Krebsrisiko und Psyche. München, Zürich: Piper; 1991.

45. Nyklicek I, Vingerhoets AJJM, Van Heck GL. Hypertension and appraisal of physical and psychological stressors. J Psychosom Res 2001;50:237-244. Hypertens 